\title{
Physical Activity of Type 2 Diabetes Mellitus Patients and Non-Diabetes Participants in Yangon, Myanmar: A Case-Control Study Applying the International Physical Activity Questionnaires (IPAQ-S)
}

\author{
Ishtiaq Ahmad' \\ Myo Nyein Aung $\mathbb{D}^{2}$ \\ Satomi Ueno $\mathbb{I D}^{1}$ \\ Ei Thinzar Khin' \\ Tint Swe Latt $\mathbb{D}^{3}$ \\ Saiyud Moolphate ${ }^{4}$ \\ Motoyuki Yuasa ${ }^{1,5}$
}

'Department of Public Health, Graduate School of Medicine, Juntendo University, Tokyo, Japan; ${ }^{2}$ Advanced Research Institute for Health Sciences and Faculty of International Liberal Arts, Juntendo University, Tokyo, Japan; ${ }^{3}$ Myanmar Diabetes Association (MMDA), Yangon, Myanmar; ${ }^{4}$ Department of Public Health, Chiang Mai Rajabhat University, Chiang Mai, Thailand; ${ }^{5}$ Faculty of International Liberal Arts, Juntendo University, Tokyo, Japan
Correspondence: Myo Nyein Aung Advanced Research Institute for Health Sciences and Faculty of International

Liberal Arts, Juntendo University, Bunkyo

City, Hongo, 2 Chome-I-I, Tokyo,

TII3-842I, Japan

$\mathrm{Tel}+8|3-38| 3-3|| \mid$

Email myo@juntendo.ac.jp
Background: Despite the evidence that physical activity (PA) can prevent type 2 diabetes mellitus (T2DM), limited research investigated the level of PA among diabetes and nondiabetes in Myanmar, where there is the escalating prevalence of diabetes recently. We investigated PA as modified the risk of diabetes, in a case-control study.

Methods: We conducted a case-control study which included 150 cases and 150 controls age 25-74 years (Mean age 43.3 \pm 14.7 years) among the cases and (55.1 \pm 10.9 years) among the controls, both sex and residence in Yangon. Cases were newly diagnosed with T2DM within six months before data collection, with laboratory-confirmed fasting blood glucose level $\geq 126 \mathrm{mg} / \mathrm{dl}$. Controls were community residents, without diabetes, confirmed with a laboratory test. The IPAQ-S was used to assess the PA level. Multiple logistic regression analysis was applied in STATA 15, using the interaction terms for age and PA, adjusting age, sex and BMI.

Results: In comparison to controls, cases were older and having less PA knowledge. The levels of vigorous PA were mean $254.9 \pm$ standard deviations (SD) $845.6 \mathrm{METs}^{\text {min.wk-1 }}{ }^{\text {among }}$ controls, 73.06 \pm 392.1 cases, moderate PA $631.5 \pm 1240.8 \mathrm{METs}^{\mathrm{min} . \mathrm{wk}-1}$ among controls and $1050.9 \pm 1601.6$ cases and walking PA $569.8 \pm 1060$ METs ${ }^{\text {min.wk-1 }}$ among controls and 777.4 \pm 1249 cases, respectively. The multiple logistic regression analysis showed adjusted odds ratios (aOR) 3.84, 95\% confidence interval (CI) 1.18-12.42 $(P<0.05)$ for those aged 40 and older, with moderate PA and aOR 18.01, $\mathrm{Cl} 6.45-50.26(P<0.001)$ for those aged 40 and older, with low PA. Comparing the strength of association, the risk of T2DM among people aged 40 and older with moderate PA is lower than age over 40 with low PA.

Conclusion: PA lessened the risk of T2DM, posted by increasing age. The findings highlighted the importance of promoting PA to reduce the T2DM prevalence in the context of Yangon, Myanmar, a low- and middle-income Asian country.

Keywords: METs, effect modification, non-communicable disease; risk of diabetes, global health, public health

\section{Introduction}

Type 2 diabetes mellitus (T2DM) is the most common metabolic disorder worldwide and its prevalence nowadays has unprecedented growth in both developed and developing countries. ${ }^{1,2}$ The global prevalence of diabetes in 2017 was approximately 425 million $(8.8 \%)$ and is expected to rise to 629 million by 2045 ; approximately $70 \%$ of this growth is predicted to occur in the developing world, as is now happening in Asia. ${ }^{3,4}$ Myanmar, 
Southeast Asia developing country is home to more than 5 million people with T2DM according to the International Federation of Diabetes and the burden is escalating fast recently. ${ }^{5}$

According to the studies, using the results of the national survey conducted in Myanmar, applying World Health Organization STEPwise approach to surveillance (WHOSTEPS) in 2014, the prevalence of diabetes was $10.5 \%$ and impaired glucose tolerance was $19.7 \%$ for the adult population aged between 25 and 64 years. ${ }^{6}$ The silent epidemic of diabetes is widespread in Myanmar, may bring many other noncommunicable diseases such as cardiovascular, strokes, disability, and deaths as its complications, resulting in heavy healthcare costs for this low-income country. Yangon Region, the most populated in Myanmar and the former capital is known to have the highest prevalence $(18.2 \%)$ of diabetes in Myanmar. ${ }^{7}$

The PA is the cornerstone of lifestyle modification aimed at preventing and managing T2DM and its related morbidities. PA has been shown to improve glycaemic control through increased insulin sensitivity and glucose tolerance. ${ }^{8}$ The increase in the incidence of T2DM has been increasing in parallel with the incidence of obesity and overweight. ${ }^{9}$ There are many health-related components of physical fitness that are positively affected by regular physical activity; body composition, cardiorespiratory resistance, body composition, muscle strength and muscular resistance. ${ }^{10}$

Regular PA benefits the health of adults with T2DM ${ }^{11}$ and also diminishes the risk of cardiovascular risk factors, notably in the prevention and management of T2DM, which is well documented. ${ }^{12,13}$ The lack of PA is the fourth leading risk factor for global mortality, despite the known hazards of being sedentary, PA levels continue to fall worldwide. ${ }^{14}$ Such physical inactivity crisis is serious in Yangon, which is very urban but its city structure is incompletely urbanized un-favouring active transportation and PA.

PA can be assessed by various approaches; The International Physical Activity Questionnaires-short form IPAQ-S was developed by the WHO in 1998 for surveillance of $\mathrm{PA}$ and to facilitate global comparisons. Concerning the research tools, the IPAQ has high reliability and validity and has been used in several studies. ${ }^{15}$ According to the intensity of the IPAQ-S, it records four types of PA: vigorous PA, moderate PA, low PA and sitting time. And the studies conducted in Myanmar considering all four domains of PA were lacking and suggested simple lifestyle interventions such as promoting a healthy diet and PA that are effective in the prevention of diabetes. ${ }^{14}$ Our present study aimed to (1) describe PA levels in a sample of Yangon resident population, (2) compare the PA levels between new diabetes patients and non-diabetes controls in Yangon and (3) determine how people with different level of PA are at the risk of type 2 diabetes mellitus, adjusting biological risk factors age, sex and BMI (body mass index).

\section{Methods}

\section{Study Design}

It was an observational study assembled in case-control study design. Cases and controls were, administered a standardized questionnaire as a validated instrument such as IPAQ-S and social demographic information. Additionally, the anthropometric measurements such as weight, height and waist circumference were provided. Fasting venous blood glucose test

Table I Inclusion and Exclusion Criteria

\begin{tabular}{|c|c|c|}
\hline & Case & Control \\
\hline Inclusion & $\begin{array}{l}\text { - Age: } 25-74 \text { years, Either sex } \\
\text { - Patients newly diagnosed with T2DM within six months before } \\
\text { data collection } \\
\text {-Diagnosed by fasting plasma glucose } \geq 126 \mathrm{mg} / \mathrm{dl} \text { and/or random } \\
\text { blood glucose (RBG) } \geq 200 \mathrm{mg} / \mathrm{dl} \text {, with or without osmotic } \\
\text { symptoms of diabetes (polyuria, polydipsia, thirst, bodyweight loss) } \\
\text { - All races and religions } \\
\text { Residence in Yangon }\end{array}$ & $\begin{array}{l}\text { - Age: } 25-74 \text { years, either sex } \\
\text { - Individuals who do not have any history of diabetes or taking } \\
\text { any diabetes medication such as oral antihyperglycemic agents } \\
\text { or insulin } \\
\text { - Fasting blood glucose }<110 \mathrm{mg} / \mathrm{dl} \text { and random blood glucose } \\
<140 \mathrm{mg} / \mathrm{dl} \\
\text { - All races and religions } \\
\text { Residence in Yangon }\end{array}$ \\
\hline Exclusion & $\begin{array}{l}\text { - In a long-term modification of diet due to any reason } \\
\text { - Institutionalized patients } \\
\text { - A person residing neither in Yangon region nor tourists or } \\
\text { foreigners }\end{array}$ & $\begin{array}{l}\text { - Non-diabetic patients with chronic diseases like kidney failure } \\
\text { - Overage and not residing in Yangon region }\end{array}$ \\
\hline
\end{tabular}


differentiated diabetes and non-diabetes status. Eligibility criteria were set for restriction of the study sample and controlling possible recall bias (Table 1).

\section{Study Setting}

The participants of this research were residents (Age: 25-74 years) of Yangon, Myanmar. The case side participants: who are newly diagnosed with T2DM within 6 months, Control side: who do not have T2DM. The sites of this study were XXX General Hospital and xxx Diabetes Special Clinic. The T2DM status of case subjects were confirmed by the clinical record whereas the controlled participants recruited from the community, after diabetes is ruled out by a prospective fasting blood glucose test.

\section{Sample Size}

The sample size was estimated using the finding in 2014 Myanmar STEP survey, $16 \%$ of the participants are physically inactive. Thus, we assumed this proportion as exposure proportion to the risk factor in the control group. Assuming those people with diabetes may have a higher proportion of exposure to the risk factor, we set the proportion of exposure among the case as $26 \%$. Using the formula for unmatched case-control study, required sample to seek a difference of these two proportions is 260. Thus, a sample of 300 will be sufficient to see the statistical significance with the power of $80 \%$ and $95 \%$ confidence interval. It also will cover the adding up $10 \%$ sample size for non-respond. The sample size was calculated by the following formula. ${ }^{16}$

$$
n=\left(\frac{r+1}{r}\right) \frac{(\bar{p})(1-\bar{p})\left(Z_{\beta}+Z_{\alpha / 2}\right)^{2}}{\left(\mathrm{p}_{1}-p_{2}\right)^{2}}
$$

\section{Case and Control Definitions}

Case: The diabetes patients determined by the fasting plasma glucose of $110-126 \mathrm{mg} / \mathrm{dL}$

Control: Non-diabetes patients with normal fasting plasma glucose. Participants in both groups were screened to meet eligibility criteria. The difference between two groups is only diabetes status (Table 1).

\section{Data Collection}

A face-to-face interview was conducted by trained interviewers. The standardized questionnaire as a validated instrument included personal demographic factors (sex,

Table 2 Socio-Demographic Characteristics of Study Participants $(n=300)$

\begin{tabular}{|c|c|c|c|c|}
\hline Variables & Control $(n=150) n(\%)$ & Case $(n=150) n(\%)$ & Value $\chi^{2}$ & $P$-value \\
\hline \multicolumn{5}{|l|}{ Age } \\
\hline Under 40 years & $71(47.3)$ & $13(8.6)$ & 55.62 & $<0.01$ \\
\hline 40 years and older & $79(52.7)$ & 137 (9|.3) & & \\
\hline \multicolumn{5}{|l|}{ Sex } \\
\hline Male & $67(44.7)$ & $47(31.3)$ & 5.65 & 0.02 \\
\hline Female & $83(55.3)$ & $103(68.7)$ & & \\
\hline \multicolumn{5}{|l|}{ Marriage status } \\
\hline Never married/Single & $62(41.3)$ & $18(12.0)$ & 35.32 & $<0.01$ \\
\hline Married & $72(48.0)$ & $99(66.0)$ & & \\
\hline Separated & $2(1.3)$ & $3(2.0)$ & & \\
\hline Divorced & $0(0.00)$ & $2(1.3)$ & & \\
\hline Widowed & $14(9.3)$ & $28(18.7)$ & & \\
\hline \multicolumn{5}{|c|}{ House hold's average monthly income } \\
\hline Less than average & $4(2.74)$ & II (7.3) & 37.55 & $<0.01$ \\
\hline Middle & $14(9.6)$ & $16(10.7)$ & & \\
\hline High & $39(26.7)$ & $80(53.3)$ & & \\
\hline Very high & $89(60.9)$ & $43(28.7)$ & & \\
\hline \multicolumn{5}{|l|}{ Level of education } \\
\hline High school completed & $61(40.2)$ & 117 (78.3) & 46.4 & $<0.01$ \\
\hline College/University completed & $80(53.7)$ & $31(20.8)$ & & \\
\hline Post graduate degree & $9(6.04)$ & I (0.7) & & \\
\hline
\end{tabular}


Table 3 Lifestyle Behaviour Risk Factors for T2DM Among Case and Control $(n=300)$

\begin{tabular}{|c|c|c|c|c|}
\hline Variables & Control $(n=150) n(\%)$ & Case $(n=150) n(\%)$ & Value $\chi^{2}$ & $P$-value \\
\hline $\begin{array}{l}\text { Hypertension } \\
\text { No } \\
\text { Yes }\end{array}$ & $\begin{array}{l}129(86.0) \\
21(14.0)\end{array}$ & $\begin{array}{l}105(70.47) \\
44(29.5)\end{array}$ & 10.4 & $<0.01$ \\
\hline $\begin{array}{l}\text { Family Diabetes history } \\
\text { No } \\
\text { Yes }\end{array}$ & $\begin{array}{l}63(47.7) \\
69(52.3)\end{array}$ & $\begin{array}{l}56(38.6) \\
89(61.4)\end{array}$ & 10.29 & 0.13 \\
\hline $\begin{array}{l}\text { Smoking } \\
\text { Never } \\
\text { Quit } \\
\text { Still smoking }\end{array}$ & $\begin{array}{l}\text { I2I (80.7) } \\
\text { II (7.3) } \\
18(12.0)\end{array}$ & $\begin{array}{l}125(83.3) \\
21(14.0) \\
4(2.7)\end{array}$ & 12.09 & $<0.01$ \\
\hline $\begin{array}{l}\text { Alcohol intake } \\
\text { Never } \\
\text { Quit } \\
\text { Regularly }\end{array}$ & $\begin{array}{l}105(70) \\
7(4.7) \\
38(25.3)\end{array}$ & $\begin{array}{l}130(86.7) \\
14(9.3) \\
6(4.0)\end{array}$ & 28.6 & $<0.01$ \\
\hline $\begin{array}{l}\text { PA knowledge } \\
\text { No } \\
\text { Yes }\end{array}$ & $\begin{array}{l}53(35.3) \\
97(64.7)\end{array}$ & $\begin{array}{l}92(61.3) \\
58(38.7)\end{array}$ & 20.3 & $<0.01$ \\
\hline $\begin{array}{l}\text { BMI } \\
\quad<22 \\
22-25 \\
>25\end{array}$ & $\begin{array}{l}40(26.7) \\
31(20.6) \\
79(52.7)\end{array}$ & $\begin{array}{l}19(12.7) \\
52(34.7) \\
79(52.7)\end{array}$ & 12.7 & $<0.01$ \\
\hline
\end{tabular}

age, and educational level), family history, smoking status, alcohol consumption, hypertension, PA knowledge and PA (IPAQ-S) within the last week (Tables 2 and 3). Current smokers were defined based on the WHO criteria, as those who self-reported smoking every day. ${ }^{17}$ Regular alcohol drinkers were defined as drinking more than twice per week for at least one year. Hypertension was screened with interview and measurement of blood pressure. We counted those who are on antihypertensive with known hypertension and we conducted blood pressure measurement. Hypertension was diagnosed if, the systolic blood pressure readings were $\geq 140 \mathrm{mmHg}$ and/or the diastolic blood pressure readings $\geq 90 \mathrm{mmHg}$ upon two repeated measurements. ${ }^{18}$ Additionally, the research participants were requested to undergo physical examinations for weight, height and waist circumference. We also provided laboratory testing of fasting venous blood to assess the blood glucose to confirm the non-T2DM status in the control group. We asked participants whether they have ever received physical education, where and when to assess their PA knowledge.

\section{Translation of Questionnaires}

The original English set of questionnaires including IPAQ$\mathrm{S}$ was translated into Myanmar language by two independent native speakers. The two translations, one each from the translators, were synthesized into a single Myanmar language version by a panel of experts consisting of the translators and the principal investigator. The panel of experts compared the two backward and forward translations with the original English version to ensure that the concept of questions had not been lost during the translations. The process of translation and adaptation of instruments was done by using WHO guidelines. ${ }^{19}$

\section{IPAQ-S Scoring}

According to IPAQ-S scoring protocol, ${ }^{20} \mathrm{METs}^{\text {min.wk-1 }}$ of a specific activity (vigorous, moderate and low-intensity PA) is computed by multiplying the MET value of particular activity (3.3 for walking, 4.0 for moderate PA, and 8.0 for vigorous PA) with hours spent in that particular activity (eg, walking METs ${ }^{\text {min.wk-1 }}=3.3 \times$ walking minutes $\times$ walking days). Only the activities lasting at least 10 minutes were taken into account. The PA was categorized using the IPAQ 
scoring protocol. The cut-off levels are based on the current guidelines for PA in the IPAQ scoring protocol as three groups: 1. "low" (some activity is reported but not enough to meet categories 2 or 3 ), 2. "moderate" (5 or more days of any combination of walking, moderate-intensity or vigorous intensity activities achieving a minimum of at least 600 METs $^{\text {min.wk-1 }}$ ) and 3. "high" (7 or more days of any combination of walking, moderate- or vigorous-intensity activities accumulating at least $\left.3000 \mathrm{METs}^{\text {min.wk-1}}\right){ }^{20}$ (Table 4)

\section{Statistical Analysis}

Differences in socio-demographic characteristics and lifestyle behaviours between the case and the control group in categorical variables were assessed by the chi-squared test. Two age categories $<40$ and $\geq 40$ years and three categories of on BMI $(<22,22-25,>25)$ were specified. A $95 \%$ confidence interval $(\mathrm{Cl})$ and $P$-value of $<0.05$ was considered significant. We used univariate logistic regression to identify factors associated with T2DM. We constructed multivariable logistic regression models to adjust for potential confounders for the association between T2DM and PA. The dependent variable was T2DM, and the independent variables were age, sex, BMI and PA to identify the odds ratio (OR) of each PA domain. To assess the associations of T2DM and PA using the logistic regression models adjusted with age, sex and BMI. Adjusted OR and their 95\% CI were calculated to test strength of association. Furthermore, we applied the interaction terms in the multivariable logistic regression model to investigate "the interaction of physical activity and age" to associate with the outcome T2DM, categorizing participants into two groups: those younger than 40 , and those aged 40 and over and into three groups: low, median and high PA. Before testing effect modification, we first tested different age stratum in the univariate analysis. The age of 40 years was the point we can start to see the significant risk of diabetes. Existing literature, WHO-STEP survey in Myanmar, had shown 45 years of age as risk factor. ${ }^{14}$ Finally, we chose earlier point for recommending earlier introduction of lifestyle intervention. All analyses were performed by using the STATA version 15.1 (Stata Corp, College Station, TX, USA)

\section{Ethical Approval}

This study was approved by the Ethical Review Board of the Juntendo University, Tokyo (authorization number 2017141) and Myanmar Ministry of Health (registry number (MHRR, PLRID-00625_V1)). Our study was conducted under the Declaration of Helsinki. The

Table 4 Physical Activity of Diabetes and Non-Diabetes in Yangon Myanmar, $2019(n=300)$

\begin{tabular}{|c|c|c|c|}
\hline Physical Activity Level & Control $n=150$ & Case $n=150$ & $P$-value \\
\hline \multicolumn{4}{|l|}{ Total PA } \\
\hline Mean \pm SD & $1456.2(2600.4)$ & $190 \mid .4(29 \mid 7.9)$ & 0.48 \\
\hline Median (IQR) & $432.75(0-1413)$ & $282.5(0-3066)$ & \\
\hline \multicolumn{4}{|c|}{ Vigorous METs min.wk-1 (8.0 METs) } \\
\hline Mean \pm SD & $254.9 \pm 845.6$ & $73.1 \pm 392.1$ & $0.01 *$ \\
\hline Median (IQR) & $0(0-0)$ & $0(0-0)$ & \\
\hline \multicolumn{4}{|c|}{ Moderate METs ${ }^{\text {min.wk-1 }}$ (4.0METs) } \\
\hline Mean \pm SD & $631.5(1240.8)$ & $1050.9(1601.6)$ & 0.13 \\
\hline Median (IQR) & $120(0-576)$ & $140(0-1680)$ & \\
\hline \multicolumn{4}{|c|}{ walking METs min.wk-1 (3.3 METs) } \\
\hline Mean \pm SD & $569.8(1060)$ & 777.4 (1249) & 0.89 \\
\hline Median (IQR) & $107.25(0-693)$ & $0(0-1 \mid 88)$ & \\
\hline PA level group ${ }^{P}$ & n (\%) & n (\%) & \\
\hline Low & $87(58.0)$ & $82(54.6)$ & $0.12^{\#}$ \\
\hline Moderate & $56(26.0)$ & $30(20.0)$ & \\
\hline High & $24(16.0)$ & $38(25.3)$ & \\
\hline
\end{tabular}

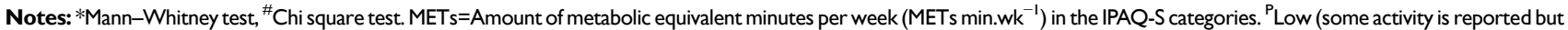
not enough to meet categories 2 or 3 ), moderate ( 5 or more days of any combination of walking, moderate-intensity or vigorous intensity activities achieving a minimum of at least 600 METsmin.wk-I) and high (7 or more days of any combination of walking, moderate- or vigorous-intensity activities accumulating at least 3000 METsmin.wk-I). ${ }^{19}$

Abbreviations: SD, standard deviation; IQR, interquartile range; PA, physical activity. 
research work and patients were recruited after informed consent was obtained. We stored the data in a computer and secured it with a password, access was limited only to the study team.

\section{Results}

We included 150 cases with T2DM and 150 controls without T2DM. Table 2 shows the social and demographic characteristics of the participants. Mean age of the study is $43.3 \pm 14.7$ years among the cases and $55.1 \pm 10.9$ years among the controls. When comparing the proportion of persons aged 40 years and older, the case group consisted of $91 \%$ and the control group $52.7 \% 40$ years and older people $(P<0.01$, Chisquare test). The case group consisted of a larger proportion of the female than the control group (68\% vs. $55.3 \%)$ $(P=0.02)$ Chi-square test $)$. However, family history of diabetes mellitus was not different between case and control group. Case group had a higher proportion of those having unhealthy behaviour such as smoking, drinking alcohol, and also being overweight significantly (Table 3 ).

Median PA level of the T2DM patients was 282.5

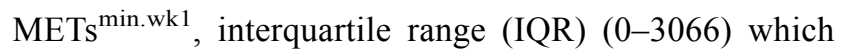
was less than median PA level of the non-diabetes controls 432.75 (IQR 0-1413). (Table 4) Specifically, the
PA level of the vigorous type of activity was significantly higher among the control group than the T2DM patients (P-0.006 Mann-Whitney test, Table 4). Comparing case and control group in the category of PA level, there was no statistically significant difference. Both groups comprised the majority having low physical activity, but the control group comprised a slightly higher proportion of persons with moderate physical activity (Table 4).

Again, when the PA level in METs ${ }^{\text {min.wk-1 }}$ was compared in three groups of PA, vigorous type of physical activity was higher among the controls than the cases. PA levels $\mathrm{MET}^{\text {min.wk-1 }}$ were compared between cases and controls within the categories of low PA, moderate PA and high PA (Figure 1). There was a higher level of vigorous activity (like heavy lifting, digging, aerobics, or fast bicycling) in the control group as compared to the case group. The mean $\pm(\mathrm{SD})$ and median and interquartile range (IQR) of vigorous $\mathrm{PA}$, moderate $\mathrm{PA}$, walking and total PA are shown in Table 4. The mean of vigorous METs $^{\text {min.wk-1 }}$ (8.0 METs) was 254.9 (845.6) among control and 73.06 (392.1) among cases. In addition, moderate METs were 631.5 (1240.8) control and 1050.9 (1601.6) cases, respectively. As the data did not show the normal

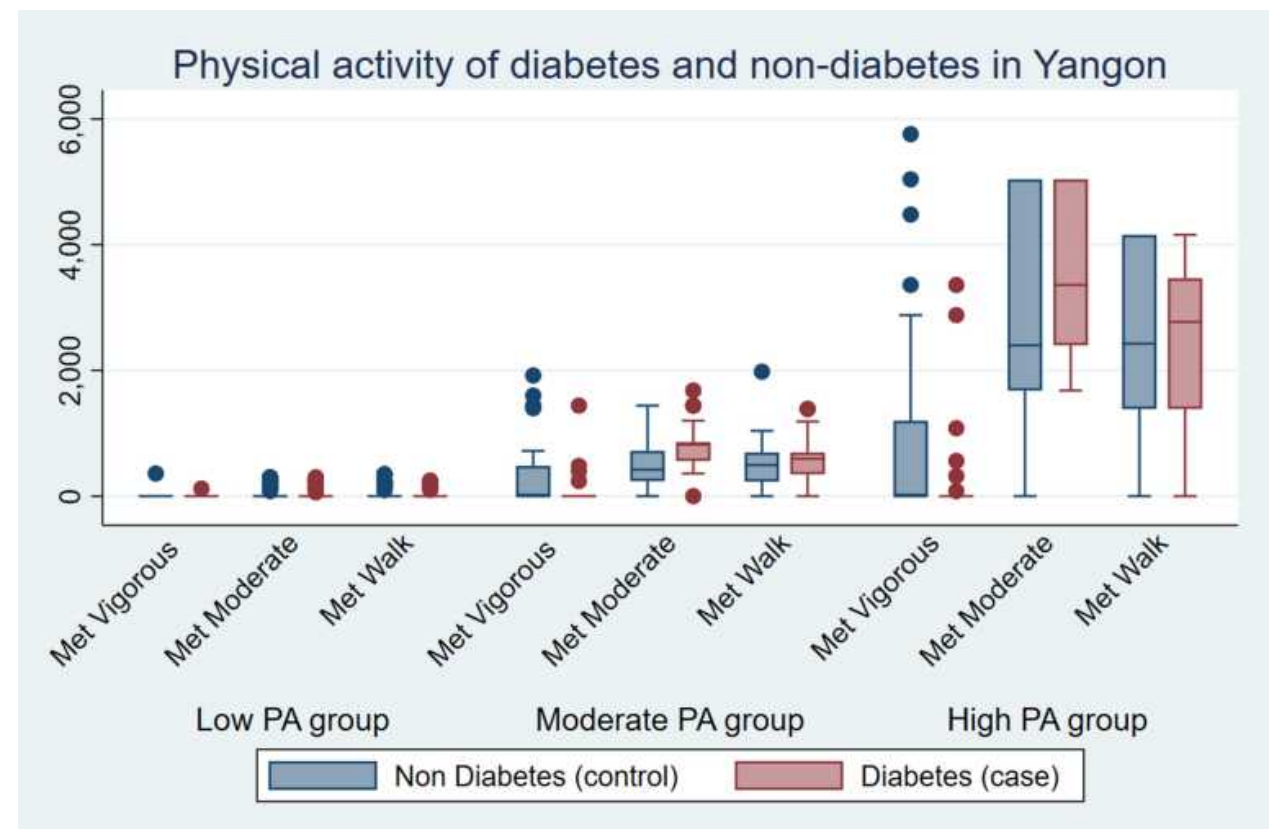

Figure I Level of physical activity (PA) in METs ${ }^{\text {min.wk-1 }}$ among diabetes patients and non-diabetes control group, within the category of low PA, moderate PA and active PA, Yangon Myanmar, $2019(\mathrm{n}=300)$.

Notes: $\mathrm{P}<0.00 \mathrm{I}$, MANOVA compared three kinds of Met level resulted from vigorous activity, moderate activity and walking between case group and control group. Low PA group (some activity is reported but not enough to meet categories 2 or 3 ), moderate PA ( 5 or more days of any combination of walking, moderate-intensity or vigorous intensity activities achieving a minimum of at least 600 METsmin.wk-I) and high PA (7 or more days of any combination of walking, moderate- or vigorous-intensity activities accumulating at least 3000 METsmin.wk-I). ${ }^{19}$ 
distribution, median and IQR values were more emphasized. Participants of the control presented a higher vigorous and moderate METs compared with the cases (Table 4). MANOVA compared three kinds of Met level resulted from vigorous activity, moderate activity and walking between case group and control group $(\mathrm{P}<0.001$, Figure 1). Within the physically active group, the level of Met due to vigorous activity was significantly higher than that of the case group (Figure 1).

Univariate logistic regression results showed a significant association of those aged 40 years and older and T2DM with an odds ratio (OR) 9.4 (95\% confidence interval (CI) 4.93-18.19). Furthermore, female gender and over-weight and obese people were likely to be T2DM too (Table 5). In contrast, people with moderate PA were less likely to be associated with T2DM OR 0.48 , CI (0.24-0.97).

We examined how physical activity level in three categories modified the association of age and T2DM, in the multiple logistic regression models, using the interaction terms, and adjusting age, sex and BMI (Table 5). Multiple logistic regression without interaction term, could not see a significant association of PA and T2DM (Data not shown).

Those aged over 40 and having low PA revealed a significantly high risk of T2DM, adjusted odds ratio (aOR)18.01 (CI) (6.45-50.26). The risk among those aged 40 and older, with moderately active was $\mathrm{OR}=3.84$
(95\% CI: 1.18-12.42), still significant but the strength of association became less. The magnitude of physical activity had defined the strength of association between T2DM and age over 40 . The strength of association with T2DM with "aged over 40 having moderate PA" was found to be weaker than those "aged over 40 having a low level of PA". PA which is a modifiable factor to T2DM was found to be significant effect modifier to the association between T2DM and age, non-modifiable biological risk factor, in a multivariable logistic regression model, after adjusting BMI and gender.

\section{Discussion}

This study revealed that patients with T2DM demonstrated a low level of physical activity compared to non-T2DM people. This study was strategically conducted in Yangon city, Myanmar. Yangon was reported to have the highest prevalence of diabetes $(18 \%)$ and prediabetes, twice of diabetes prevalence, according to Myanmar national STEP survey $2014 .^{21}$ In that survey, Latt et al reported the increased risk of diabetes with increasing age highlighting urban residence as the high-risk location for T2DM in Myanmar. ${ }^{14}$

Therefore, it is important to specify modifiable lifestyle risk factors in such a risk setting applying epidemiological study before launching public health intervention. ${ }^{22}$ The most feasible, effective and the quickest way is case-control study situated in that

Table 5 Investigating the Effect of Physical Activity Upon Risk Factors of Type 2 Diabetes, Case-Control Study ( $\mathrm{n}=300)$

\begin{tabular}{|c|c|c|c|c|c|c|}
\hline \multirow[t]{2}{*}{ Variable } & \multirow{2}{*}{$\begin{array}{l}\text { Control=150 } \\
n(\%)\end{array}$} & \multirow{2}{*}{$\begin{array}{l}\text { Case }=150 \\
\text { n (\%) }\end{array}$} & \multicolumn{2}{|c|}{ Univariate Analysis } & \multicolumn{2}{|l|}{ Multivariable Analysis } \\
\hline & & & OR 95\%Cl & $P$-value & Adjusted OR 95\% Cl & $P$-value* \\
\hline Female & $83(55.3)$ & $103(68.7)$ & Ref & & Ref & \\
\hline Male & $67(44.7)$ & $47(31.3)$ & $0.56(0.35-0.90)$ & 0.02 & $1.7(1.01-3.01)$ & $<0.05$ \\
\hline Low PA & $87(58.0)$ & $82(54.6)$ & Ref & & Ref & \\
\hline Moderate PA & $56(26.0)$ & $30(20.0)$ & $0.48(0.24-0.97)$ & $<0.05$ & $0.53(0.09-3.06)$ & 0.49 \\
\hline High PA & $24(16.0)$ & $38(25.3)$ & $0.59(0.32-1.07)$ & 0.09 & $0.19(0.03-1.05)$ & 0.06 \\
\hline BMI $<22$ & $40(26.7)$ & $19(12.7)$ & Ref & & Ref & \\
\hline BMI $22-25$ & $31(20.6)$ & $52(34.7)$ & $3.53(1.74-7.14)$ & $<0.001$ & $1.83(0.80-4.17)$ & 0.15 \\
\hline BMI $>25$ & $79(50.0)$ & $79(50.0)$ & $2.10(1.12-3.94)$ & $<0.05$ & $1.02(0.47-2.18)$ & 0.96 \\
\hline Age $<40$ & 7I (47.3) & $13(8.6)$ & Ref & & Ref & \\
\hline Age $\geq 40$ & $79(52.7)$ & $137(9 \mid .3)$ & $9.4(4.93-18.19)$ & $<0.001$ & & \\
\hline \multicolumn{7}{|l|}{ Age \# METs Categories } \\
\hline$\geq 40 \#$ High PA & & & & & $3.19(0.69-14.74)$ & 0.14 \\
\hline$\geq 40 \#$ Moderate PA & & & & & $3.84(1.18-12.42)$ & $<0.05$ \\
\hline$\geq 40$ \# Low PA & & & & & $|8.0|(6.45-50.26)$ & $<0.001$ \\
\hline
\end{tabular}

Notes: *Controlled if the total METs are equal to zero. Age \# METs Categories (modification term), Adjusted for age sex and BMI. 
particular social and cultural setting. ${ }^{23}$ Furthermore, no previous study measured the level of physical activity using a validated instrument like IPAQ-S in Yangon where the silent epidemic of diabetes is occurring amidst the trendy sedentary lifestyle and increasing motorization. $^{6,14}$

That was the reason why we conducted a case-control study in Yangon, performing an accurate measurement of $\mathrm{PA}$ and investigating its association with diabetes and risk factor especially age, reported in national STEP survey. ${ }^{21}$ We set the eligibility criteria similar to national survey with a strict definition of case and control and being residents of Yangon to specify the study domain.

The IPAQ-S measures PA level in METs. It was transculturally validated and applied to new diabetes patients and controls who are residents of the urban community in Yangon. Forward and backward translation, cognitive tests and pilot study preceded the actual study ensuring the reliability of the instrument. ${ }^{19}$

The findings showed that there is an increasing risk of diabetes in older age specifically, 40 years and older (Tables 1 and 5). The prevalence of DM in the Yangon Region was generally increasing with age, which is similar to previous studies among Asian Indians and Chinese population. ${ }^{24-28}$ As for the lifestyle behaviour risk factors of T2DM, previous studies have indicated that physical inactivity, ${ }^{24}$ smoking, ${ }^{25}$ and alcohol consumption ${ }^{26}$ may increase the risk of diabetes, the findings of our study are consistent (Table 2, 3). Smoking leads to insulin resistance through various underlying effects, including oxidative stress, inflammation, and endothelial dysfunction. ${ }^{27}$ Alcohol intake also interferes with glucose metabolism in the body, thus increasing blood glucose levels. Previous studies have shown that hypertension, dyslipidaemia, and CHD (coronary heart disease) frequently occur together with diabetes, indicating that a significant association exists between these diseases and glucose metabolism. ${ }^{24}$ The study also showed that BMI significantly associated with T2DM, the increased BMI were found to be associated with an increased risk of T2DM in previous studies. ${ }^{28}$ Our study added evidence for a modifiable risk factor physical in activity.

PA levels reported in the results of current study were relatively less than those reported in the study conducted in 20 countries worldwide using the same instrument (IPAQ-S). ${ }^{29}$ (Table 4) This is also in the agreement with previous studies which found that lower exercise capacity is common in patients with T2DM. ${ }^{30,31}$

Equally distributed low level of PA among cases and controls in the current study indicated that population-level PA promotion interventions are required in Yangon, Myanmar (Table 4). The mean \pm sd of Vigorous METs ${ }^{\text {min.wk-1 }}$ found lower in cases as compared to controls (Figure 1). The categorical scores of IPAQ-s showed that $20 \%$ of participants showed moderate PA (five or more days of any combination of walking, moderate-intensity or vigorous-intensity activities achieving a minimum Total physical activity of at least 600 MET-minutes/week) of cases and higher scores found among controls (Table 4).

A cross-sectional study by Aung et al, comparing the urban and rural prevalence of diabetes mellitus of the Yangon Region found low physical activity was associated with T2DM. ${ }^{5}$ In addition, Aekplakorn et al, in neighbouring Thailand showed that low physical activity together with a high carbohydrate intake pattern increased the risk of metabolic syndrome. ${ }^{32}$ The rapid rise in diabetes prevalence concurs with findings in other Asian countries, like China, Malaysia, South Korea, Taiwan and Singapore. ${ }^{33}$ A previous systematic review highlighted that exercising regularly is effective in improving insulin sensitivity, and mentioned that both aerobic along with resistance training have comprehensive benefits to patients with diabetes. ${ }^{34}$

We also identified that people acquired a low level of PA knowledge as most of the respondents answered that they got PA knowledge from diabetes clinics just after being diagnosed with diabetes (Table 1). It would highlight the need for physical education which is launched earlier such as in the primary schools and in the communities. ${ }^{35}$ This result corresponds with the findings of Hui et al, a study of Chinese adults with T2DM, where those participants who were knowledgeable about appropriate exercise prescription exhibited higher levels of PA than those who were short of relevant knowledge. ${ }^{36}$

Moreover, comparing cases and control within the high, moderate and low PA categories identified that METs level acquired through moderate and vigorous PA is high among the control (Figure 1 and Table 4). Further analysis identified a very high risk of T2DM among Yangon residents, aged over 40, having low PA and a slighter lower risk among those with moderate PA (Table 5). This result was confirmed in the multivariable model, adjusting age, sex and BMI. Diabetic individuals engaged in physical exercise for at least 30 minutes/day 
present better glycemic control and lower medication use than sedentary ones. ${ }^{37}$ Insulin sensitivity, which is one of the mechanisms of diabetes, is improved by moderate to high level of PA. ${ }^{38}$ There is a well-documented beneficial effect of physical activity among type 2 diabetic individuals, higher physical fitness. ${ }^{39}$ Likewise, the present study observed the same patterns of association between habitual physical activity and diabetes.

The finding in our study identified who are at acquired risk of diabetes in addition to biological risk factor which is age. Importantly we identified modifiable lifestyle risk factor, "physical inactivity". ${ }^{30}$ It would help health authority for guiding policy and preventive intervention in several ways. We recommended that physical activity promotion intervention becomes mandatory for those aged older than 40 and living in Yangon and similar communities across Myanmar and Asia. It might push medical professionals to prescribe "exercise as medicine" for preventing diabetes individually. ${ }^{40}$ Therefore, preventive intervention such as screening and early lifestyle changes to promote physical activity should be prioritized to high-risk persons, based on the current study findings.

However, as the country is having a large proportion of its population at the risk of diabetes and prediabetes, promoting PA in a population approach would be more suitable than the high-risk approach. PA represents a health behavior, an informed choice, resulting from individual self-efficacy, walkable environment, city landscape favoring active transportation, sports facilities, public spaces and ultimately the social determinants. ${ }^{41}$ This situation dictates health promotion empowering communities. ${ }^{42}$ Therefore, the future study may aim to identify social determinants causing inequality of PA in Myanmar.

Patients with chronic diseases who received sufficient information and education are known to have a better quality of life and PA physical activity level. ${ }^{43}$ Lack of professional guidance, lack of accessibility to exercise facilities, and lack of awareness of where or how to exercise were major barriers to be physically active. ${ }^{44}$ Newly diagnosed T2DM may not experience physical constraints; however, changing well-established habits, negative perceptions of the "new" or recommended diabetes regimen, together with a lack of knowledge and understanding of how to live with T2DM may act as barriers to being physically active. ${ }^{43}$

The total METs ${ }^{\text {min.wk-1 }}$ analysis showed the higher level of vigorous activity in the control group as the case group did not meet the criterion of the frequency of vigorous- and moderate-intensity PA. The physical activity of such frequency is regarded nowadays as benefits for health ${ }^{45,46}$ a previous study, Booth et al; found that T2DM patients with low activity level had shorter life expectancy by about 0.1-0.5 years compared to patients with moderate-to-high activity levels. ${ }^{43}$ Therefore, our finding also recommended that it is urgent and important to increase the PA level of diabetes patients in Myanmar, to secure their healthy life.

The study has several strengths; this is the first case-control study to examine the associated risk factors as PA with T2DM in the suburb of Yangon, Myanmar. Thus, the findings of this study may provide valuable hints to strategize health promotion targeting physical education and PA promotion among diabetes and the general public. We included all laboratoryconfirmed cases and a random sample of laboratory-confirmed controls. We refrained from including clinically diagnosed study participants with chronic diseases to reduce the risk of misclassification errors. It will have limitations although those have been minimized. There is a possibility of recall bias in the nature of the case-control study. It might be reduced by applying IPAQ-S which detects the physical activity level in the previous seven days. Although diabetes patients are new according to the definition, they might have received lifestyle modification message from diabetes clinics that might influence the PA level. Unmatched case-control study design can be considered as a limitation. However, it allowed us to have community controls which better served to be more realistic control groups. Moreover, we adjusted possible confounders with strict criteria of eligibility to ensure the study domain and multivariable analysis to control possible confounders. Therefore, the findings are expected to be replicable in other settings.

\section{Conclusion}

Our study found that physically inactive persons are at risk of T2DM especially those over age 40 years. Therefore, adequate PA is mandatory to reduce the prevalence of developing T2DM among urban residents in Yangon and similar cities. These findings are expected to have significant implications for the prevention of diabetes in Myanmar. Promoting PA, particularly among older adults aged 40 years and above, should constitute a major task for public health to prevent T2DM in Myanmar and countries with similar context. Further research using a prospective cohort study design and a larger sample from multiple centres is needed to consolidate these findings. 


\section{Data Sharing Statement}

The data used for this study is available can be provided on request. Myanmar version IPAQ-S will be shared upon request.

\section{Acknowledgments}

We acknowledge the goodwill of the participants of this research.

\section{Funding}

This work was supported by JSPS KAKENHI Grant Number 18K10110.

\section{Disclosure}

The authors report no conflicts of interest in this work.

\section{References}

1. Ariza MA, Vimalananda VG, Rosenzweig JL. The economic consequences of diabetes and cardiovascular disease in the United States. Rev Endocr Metab Disord. 2010;11(1):1-10. doi:10.1007/s11154010-9128-2

2. Fonseca VA, Smith H, Kuhadiya N, et al. Impact of a natural disaster on diabetes. Exacerb Dispar Long Term Conseq. 2009;32(9):1632-1638.

3. Cho N, Shaw J, Karuranga S, et al. IDF Diabetes Atlas: global estimates of diabetes prevalence for 2017 and projections for 2045 . Diabetes Res Clin Pract. 2018;138:271-281. doi:10.1016/j. diabres.2018.02.023

4. Wild S, Roglic G, Green A, Sicree R, King H. Global prevalence of diabetes: estimates for the year 2000 and projections for 2030. Diabetes Care. 2004;27(5):1047-1053. doi:10.2337/diacare.27.5.1047

5. Aung WP, Htet AS, Bjertness E, Stigum H, Chongsuvivatwong V, Kjøllesdal MKR. Urban-rural differences in the prevalence of diabetes mellitus among 25-74 year-old adults of the Yangon Region, Myanmar: two cross-sectional studies. BMJ Open. 2018;8(3): e020406. doi:10.1136/bmjopen-2017-020406

6. Aung WP, Bjertness E, Htet AS, Stigum H, Kjøllesdal MKR. Trends in diabetes prevalence, awareness, treatment and control in Yangon Region, Myanmar, between 2004 and 2014, two cross-sectional studies. Int $J$ Environ Res Public Health. 2019;16(18):3461. doi:10.3390/ijerph16183461

7. Latt TS, Aye TT, Ko K, et al. Myanmar diabetes care model: bridging the gap between urban and rural healthcare delivery. J ASEAN Fed Endocr Soc. 2015;30(2):105. doi:10.15605/jafes.030.02.16

8. Eriksson KF, Lindgärde F. Prevention of type 2 (non-insulindependent) diabetes mellitus by diet and physical exercise. The 6-year Malmö feasibility study. Diabetologia. 1991;34(12):891-898. doi:10.1007/BF00400196

9. Alberti G, Zimmet P, Shaw J, Bloomgarden Z, Kaufman F, Silink M. Type 2 diabetes in the young: the evolving epidemic: the International Diabetes Federation consensus workshop. Diabetes Care. 2004;27(7):1798-1811. doi:10.2337/diacare.27.7.1798

10. Ferguson B. ACSM's guidelines for exercise testing and prescription 9th Ed. 2014. J Can Chiropr Assoc. 2014;58(3):328.

11. Luke A, Dugas LR, Durazo-Arvizu RA, Cao G, Cooper RS. Assessing physical activity and its relationship to cardiovascular risk factors: NHANES 2003-2006. BMC Public Health. 2011;11:387. doi:10.1186/1471-2458-11-387
12. Kohl HW, Craig CL, Lambert EV, et al. The pandemic of physical inactivity: global action for public health. Lancet. 2012;380 (9838):294-305. doi:10.1016/S0140-6736(12)60898-8

13. Xu Y, Wang L, He J, et al. Prevalence and control of diabetes in Chinese adults. JAMA. 2013;310(9):948-959. doi:10.1001/ jama.2013.168118

14. Latt T-S, Zaw -K-K, Ko K, et al. Measurement of diabetes, prediabetes and their associated risk factors in Myanmar 2014. Diabetes Metab Syndr Obes. 2019;12:291-298. doi:10.2147/DMSO.S156270

15. Craig CL, Marshall AL, Sjöström M, et al. International physical activity questionnaire: 12-country reliability and validity. Med Sci Sports Exerc. 2003;35(8):1381-1395. doi:10.1249/01.MSS.00000789 24.61453.FB

16. Charan J, Biswas T. How to calculate sample size for different study designs in medical research? Indian J Psychol Med. 2013;35 (2):121-126. doi:10.4103/0253-7176.116232

17. World Health Organization. Guidelines for the Conduct of Tobacco Smoking Survey of the General Population: Report of a WHO Meeting Held in Helsinki, Finland, 29 November4 December 1982. World Health Organization; 1983.

18. Beaney T, Schutte AE, Stergiou GS, et al. May measurement month 2019. Hypertension. 2020;76(2):333-341. doi:10.1161/HYPER TENSIONAHA.120.14874

19. Process of translation and adaptation of instruments; 2020. Available from: https://www.who.int/substance_abuse/research_tools/transla tion/en/. Accessed June 7, 2020.

20. IPAQ. International physical activity questionnaire; 2005. Available from: http://www.ipaq.ki.se. Accessed May 14, 2020.

21. WHO Sr. World Health Organization, report on national survey of diabetes mellitus and risk factors for Non-communicable Diseases (NCDs) in Myanmar; 2014. Available from: https://www.who.int/ ncds/surveillance/steps/Myanmar_2014_STEPS_Report.pdf. Accessed February 25, 2021.

22. Colberg SR, Sigal RJ, Fernhall B, et al. Exercise and type 2 diabetes. Am Coll Sports Med Am Diabetes Assoc. 2010;33(12):2692-2696.

23. Fletcher GS. Clinical Epidemiology: The Essentials. Lippincott Williams \& Wilkins; 2019.

24. Buckley CM, Madden J, Balanda K, et al. Pre-diabetes in adults 45 years and over in Ireland: the survey of lifestyle, attitudes and nutrition in Ireland 2007. Diabet Med. 2013;30(10):1198-1203. doi:10.1111/dme.12226

25. Houston TK, Person SD, Pletcher MJ, Liu K, Iribarren C, Kiefe CI. Active and passive smoking and development of glucose intolerance among young adults in a prospective cohort: CARDIA study. $B M J$. 2006;332(7549):1064-1069. doi:10.1136/bmj.38779.584028.55

26. Nakanishi N, Suzuki K, Tatara K. Alcohol consumption and risk for development of impaired fasting glucose or type 2 diabetes in middle-aged Japanese men. Diabetes Care. 2003;26(1):48-54. doi:10.2337/diacare.26.1.48

27. Akter S, Goto A, Mizoue T. Smoking and the risk of type 2 diabetes in Japan: a systematic review and meta-analysis. $J$ Epidemiol. 2017;27(12):553-561. doi:10.1016/j.je.2016.12.017

28. Tao L-X, Yang K, Huang -F-F, et al. Association of waist circumference gain and incident prediabetes defined by fasting glucose: a seven-year longitudinal study in Beijing, China. Int J Environ Res Public Health. 2017;14(10):1208. doi:10.3390/ijerph14101208

29. Naidoo J, Wills J. Foundations for Health Promotion-E-Book. Elsevier Health Sciences; 2016. Foundations for Health PromotionE-Book.

30. Shephard RJ. Physical Activity and Health Guidelines: Recommendations for Various Ages, Fitness Levels, and Conditions from 57 Authoritative Sources. Leeds: Human Kinetics; 2010.

31. Zeleke Negera G, Charles Epiphanio D. Prevalence and predictors of nonadherence to diet and physical activity recommendations among type 2 diabetes patients in Southwest Ethiopia: a cross-sectional study. Int J Endocrinol. 2020;2020:1512376. doi:10.1155/2020/1512376 
32. Aekplakorn W, Satheannoppakao W, Putwatana P, et al. Dietary pattern and metabolic syndrome in Thai adults. J Nutr Metab. 2015;2015:468759. doi:10.1155/2015/468759

33. Danaei G, Finucane MM, Lu Y, et al. National, regional, and global trends in fasting plasma glucose and diabetes prevalence since 1980: systematic analysis of health examination surveys and epidemiological studies with 370 country-years and 2.7 million participants. Lancet. 2011;378(9785):31-40. doi:10.1016/S0140-6736(11)60679-X

34. Shawahna R, Batta A, Asa'ad M, Jomaah M, Abdelhaq I. Exercise as a complementary medicine intervention in type 2 diabetes mellitus: a systematic review with narrative and qualitative synthesis of evidence. Diabetes Metab Syndr. 2021;15(1):273-286. doi:10.1016/ j.dsx.2021.01.008

35. Timpel P, Harst L, Reifegerste D, Weihrauch-Blüher S, Schwarz PEH. What should governments be doing to prevent diabetes throughout the life course? Diabetologia. 2019;62 (10):1842-1853. doi:10.1007/s00125-019-4941-y

36. Hui SS-C, Hui GP-S, Xie YJ, Dalby AR. Association between physical activity knowledge and levels of physical activity in Chinese adults with type 2 diabetes. PLoS One. 2014;9(12): e115098. doi:10.1371/journal.pone.0115098

37. Bertoldi AD, Hallal PC, Barros AJD. Physical activity and medicine use: evidence from a population-based study. BMC Public Health. 2006;6(1):224. doi:10.1186/1471-2458-6-224

38. Nguyen TN, Nguyen TT, Hagströmer M, et al. Physical activity and plasma glucose control among diabetic patients attending outpatients clinics in Hanoi, Vietnam. Int J Environ Res Public Health. 2021;18 (3):1182. doi:10.3390/ijerph18031182

39. Kadoglou NP, Iliadis F, Angelopoulou N, et al. Cardiorespiratory capacity is associated with favourable cardiovascular risk profile in patients with type 2 diabetes. J Diabetes Complications. 2009;23 (3):160-166. doi:10.1016/j.jdiacomp.2007.12.008
40. Pedersen BK, Saltin B. Exercise as medicine - evidence for prescribing exercise as therapy in 26 different chronic diseases. Scand J Med Sci Sports. 2015;25(Suppl 3):1-72.

41. Viswanath KGBKRK. Health Behavior: Theory, Research, and Practice. 5th ed. San Francisco, CA: Jossey-Bass, a Wiley Brand; 2015.

42. Naidoo J, Wills J. Foundations for Health Promotion. E-Book: Elsevier Health Sciences 2016.

43. Booth AO, Lowis C, Dean M, Hunter SJ, McKinley MC. Diet and physical activity in the self-management of type 2 diabetes: barriers and facilitators identified by patients and health professionals. Prim Health Care Res Dev. 2013;14(3):293-306. doi:10.1017/ S1463423612000412

44. Lidegaard LP, Schwennesen N, Willaing I, Faerch K. Barriers to and motivators for physical activity among people with Type 2 diabetes: patients' perspectives. Diabet Med. 2016;33(12):1677-1685. doi: $10.1111 /$ dme. 13167

45. Haskell WL, Lee IM, Pate RR, et al. Physical activity and public health: updated recommendation for adults from the American College of Sports Medicine and the American Heart Association. Med Sci Sports Exerc. 2007;39(8):1423-1434. doi:10.1249/ mss.0b013e3180616b27

46. WHO. Global recommendations on physical activity for health. WHO: Geneva; 2010. Available from: http://www.who.int/dietphysi calactivity/factsheet_. Accessed February 25, 2021.

Diabetes, Metabolic Syndrome and Obesity: Targets and Therapy

Dovepress

\section{Publish your work in this journal}

Diabetes, Metabolic Syndrome and Obesity: Targets and Therapy is an international, peer-reviewed open-access journal committed to the rapid publication of the latest laboratory and clinical findings in the fields of diabetes, metabolic syndrome and obesity research. Original research, review, case reports, hypothesis formation, expert opinion and commentaries are all considered for publication. The manuscript management system is completely online and includes a very quick and fair peer-review system, which is all easy to use. Visit http://www.dovepress.com/testimonials.php to read real quotes from published authors

Submit your manuscript here: https://www.dovepress.com/diabetes-metabolic-syndrome-and-obesity-targets-and-therapy-journal 